SCIREA Journal of Electrical Engineering http://www.scirea.org/journal/DEE

June 29, 2021

Volume 6, Issue 3, June 2021

\title{
Autonomous Operation of an Islanded Inverter enabled by Robust Droop Control
}

\section{Basil Issac}

AMETEK Instruments India Pvt. Ltd., Bangalore, India

Email: basil.issac@ametek.com, basilisaac@yahoo.com

\begin{abstract}
A microgrid is a new concept that has changed the power systems dramatically. This paper focuses on the autonomous operation of an Islanded inverter. The manuscript deals with the design of micro grid in island mode. There are several methods to control a microgrid. Among them droop control deals with change of active and reactive power to change in frequency and supply voltage respectively. The aim is to design an island mode inverter and to study its changes in active and reactive power with frequency and voltage in MATLAB while the load is resistive and nonlinear in nature. Also, contrive a voltage quality controller to improve the voltage harmonics and to achieve tight output voltage regulation through the implementation of a special notch filter in the controller algorithm.
\end{abstract}

Keywords: Robust Droop control, R Inverter, C Inverter, L Inverter, THD (Total Harmonic distortion). 


\section{Conventional droop controller: $\mathbf{R}$ inverter}

It is well known that the output impedance of inverters is often inductive because of the filter inductor and the transfer line impedance. In some low power systems, the inverter output impedance could be dominantly resistive. Droop control deals with change of active and reactive power with change in frequency and supply voltage respectively. In droop control, we deal with voltage vr, amplitude $\mathrm{E}$ and phase $\delta$. This is very similar to like a two-inputtwo-output system,

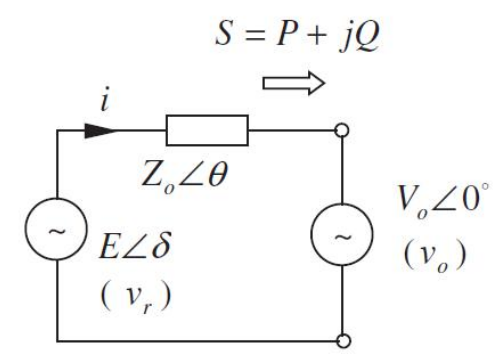

Figure:1 Power delivered to a voltage source through an impedance.

Referring to Fig:1, when the output impedance is resistive, the phase angle between current and voltage $\theta=0 \circ$. The real and reactive power delivered by the source to the terminal via the impedance can be obtained as follows,

$\mathrm{i}=\mathrm{E}<\delta-\mathrm{Vo}_{\mathrm{o}}<0^{\circ} /\left(\mathrm{Zo}_{\mathrm{o}}<\theta\right)$

$=\left(\mathrm{E} \cos \delta-\mathrm{V}_{\mathrm{o}}+\mathrm{j} \mathrm{E} \sin \delta\right) /\left(\mathrm{Zo}_{\mathrm{o}}<\theta\right)$

$\mathrm{P}=\mathrm{Evo} / \mathrm{Zo}^{*} \cos \delta-\mathrm{Vo}^{\wedge} 2 / \mathrm{Zo}$,

and $\mathrm{Q}=-\mathrm{Evo} / \mathrm{Zo}^{*} \sin \delta$

When $\delta$ is small in value then,

$\mathrm{P} \approx \mathrm{Vo} / \mathrm{Zo}^{*} \mathrm{E}-\mathrm{Vo}^{\wedge} 2 / \mathrm{Zo}$

and $\mathrm{Q} \approx-\mathrm{Evo} / \mathrm{Zo}^{*} \delta$,

and, approximately we can write the expression as below

$\mathrm{P} \sim \mathrm{E}$ and $\mathrm{Q} \sim-\delta$. 
The above expression says that the Real or active power $(\mathrm{P})$ is proportional to the Voltage, where the reactive power $(\mathrm{Q})$ is proportional to the negative of the phase angle.

Where means in proportion to. Hence, the conventional droop control strategy can be expressed as,

$$
\begin{aligned}
& \mathrm{Ei}=\mathrm{E} *-\text { ni Pi, } \\
& \omega \mathrm{i}=\omega *+\text { mi Qi }
\end{aligned}
$$

Where 'ni' and 'mi' are droop coefficients:

For $\mathrm{R}$ inverters we can express the equation (1) and (2) as shown in figure 2
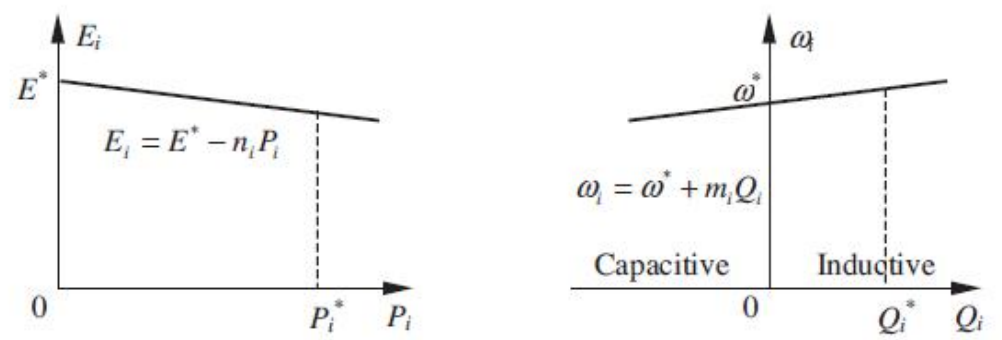

Figure:2 R-Inverter conventional droop control

\section{Conventional droop controller: L Inverter}

When the output impedance is inductive, the phase angle between current and voltage

$\theta=90 \circ$. The current lags the voltage by $90^{\circ}$. Then,

$\mathrm{P}=\mathrm{Evo} / \mathrm{Zo}^{*} \sin \delta$

and $\mathrm{Q}=\mathrm{Evo} / \mathrm{Zo}^{*} \cos \delta-\mathrm{Vo} 2 / \mathrm{Zo}$.

When $\delta$ is small in value then,

$\mathrm{P} \approx \mathrm{EVo} / \mathrm{Zo}_{0} * \delta$

and $\mathrm{Q} \approx \mathrm{Evo} / \mathrm{Zo}-\mathrm{Vo} 2 / \mathrm{Zo}$,

and, approximately we can write the expression as below

$\mathrm{P} \sim \delta$ and $\mathrm{Q} \sim \mathrm{E}$. 
The above expression declares that the Real or active power $(\mathrm{P})$ is proportional to the Phase angle, where the reactive power $(\mathrm{Q})$ is proportional to the voltage.

Therefor we can write the expression for the conventional L inverter as follows,

$$
\begin{aligned}
& \mathrm{Ei}=\mathrm{E} *-\mathrm{ni} \mathrm{Q}, \\
& \omega \mathrm{i}=\omega *-\mathrm{mi} \mathrm{Pi},
\end{aligned}
$$

For L inverters we can express the equation (3) and (4) as shown in figure 3
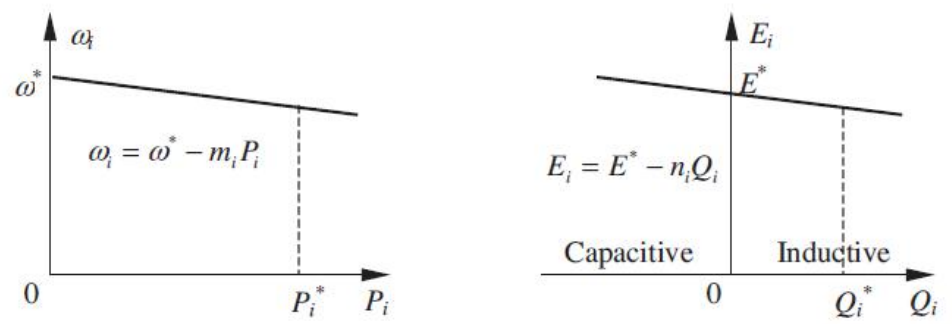

Figure:3 L-Inverter conventional droop control

\section{Conventional droop controller: C Inverter}

When the output impedance is capacitive, The phase angle between current and voltage

$\theta=-90^{\circ}$. The current leads the voltage by $90^{\circ}$. Then we can write the expression as,

$\mathrm{P}=-\mathrm{Evo} / \mathrm{Zo}_{0} * \sin \delta$

and $\mathrm{Q}=-\mathrm{Evo} / \mathrm{Zo}^{*} \cos \delta+\mathrm{Vo} 2 / \mathrm{Zo}$.

When $\delta$ is small in value then,

$\mathrm{P} \approx-\mathrm{EVo} / \mathrm{Zo}_{0} * \delta$

and $\mathrm{Q} \approx-\mathrm{Evo} / \mathrm{Zo}+\mathrm{Vo} 2 / \mathrm{Zo}$,

and, approximately we can write the expression as below,

$\mathrm{P} \sim-\delta$ and $\mathrm{Q} \sim-\mathrm{E}$.

The above expression says that the Real or active power $(\mathrm{P})$ is proportional to the negative of the phase angle, where the reactive power $(\mathrm{Q})$ is proportional to the negative of the voltage.

Therefor we can write the expression for the conventional $\mathrm{C}$ inverter as below, 


$$
\begin{aligned}
& \mathrm{Ei}=\mathrm{E} *+\operatorname{ni} \mathrm{Q}, \\
& \omega \mathrm{i}=\omega *+\mathrm{mi} \mathrm{Pi},
\end{aligned}
$$

For $\mathrm{C}$ inverters we can express the equation (5) and (6) as shown in figure 4:
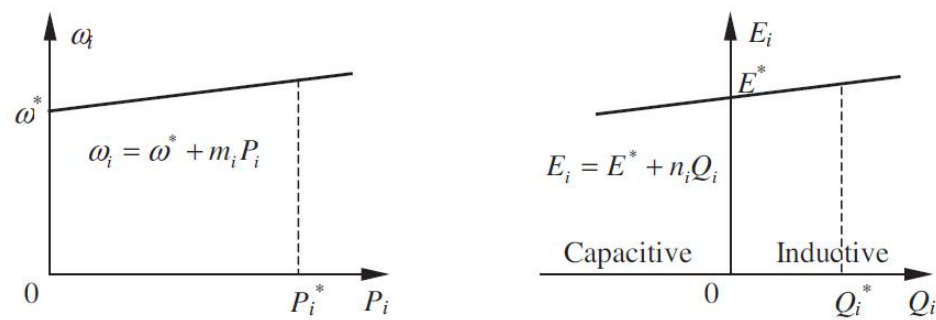

Figure:4 C-Inverter conventional droop control

\section{Iv. Conventional droop control}

The main principle of droop control is to use the exchange of active and reactive power between a generator or storage unit and the grid to control the grid voltage magnitude and frequency. The grid impedance of the transmission line is mainly inductive and thus the grid voltage magnitude is influenced mostly by reactive power. The active power influences grid voltage phase angle or frequency.

Droop controller has got lots of advantages over the conventional control algorithms. With droop controller the system doesn't require a master/Slave concept, all units are equal, communication not required between the inverters, number of units not limited, distance not limited.

A MATLAB simulation is performed with the below parameters for conventional, Robust droop and Robust droop with harmonics reduction to eliminate the dominant harmonics. The simulation of the model was done for Input DC-bus voltage: $30 \mathrm{~V} \mathrm{DC}$, Switching frequency: $20 \mathrm{kHz}$, System frequency: $50 \mathrm{~Hz}$, Rated output voltage (RMS): $12 \mathrm{~V} \mathrm{AC}$, Rated power of Inverter: $50 \mathrm{VA}$ with power factor 0.9, Filter inductor: $2.35 \mathrm{mH}$ with parasitic resistance: 0.1 $\Omega$, Filter capacitor: $22 \mu \mathrm{F}$, Resistive Load: $9 \Omega$, Non-linear load: a single-phase diode bridge rectifier supplying a $9 \Omega$ load through an LC filter $(2.2 \mathrm{mH}, 220 \mu \mathrm{F})$ 
This section of the paper defines the performances of conventional droop controller with linear and nonlinear load.

\section{a) Conventional Droop controller - Linear load}

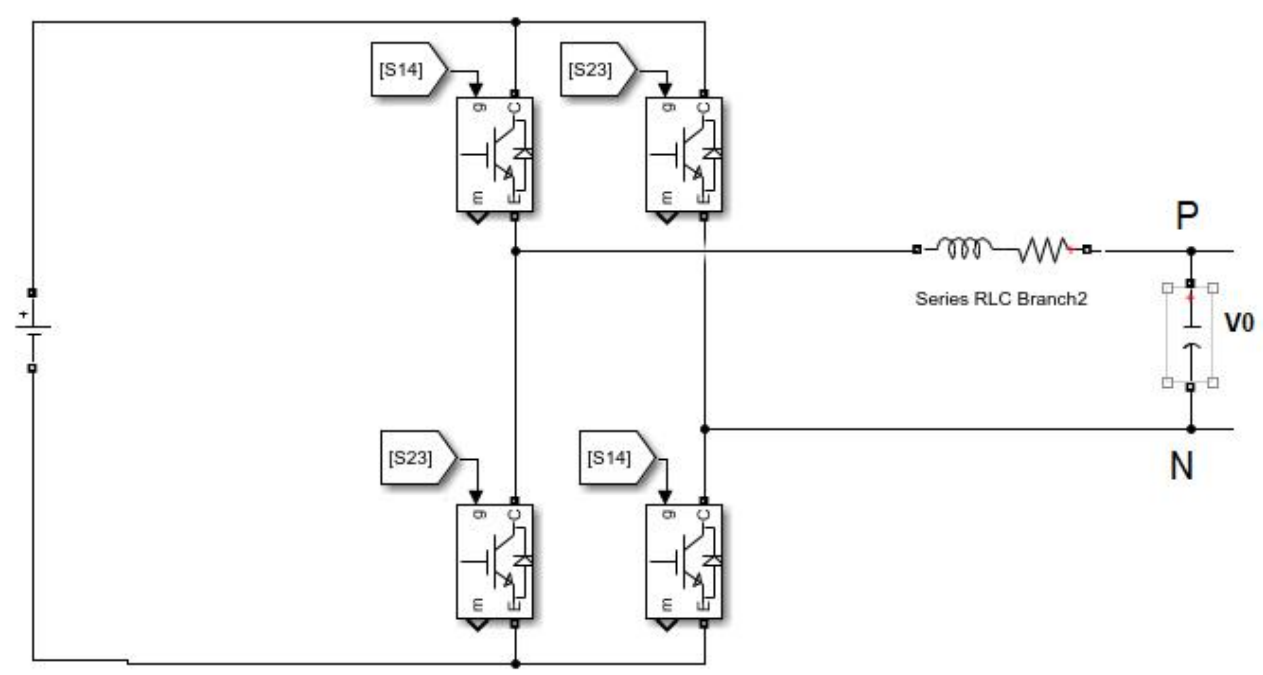

\section{Figure:5}

Figure5 shows the power block implementation of the inverter common to R, L and C inverter.

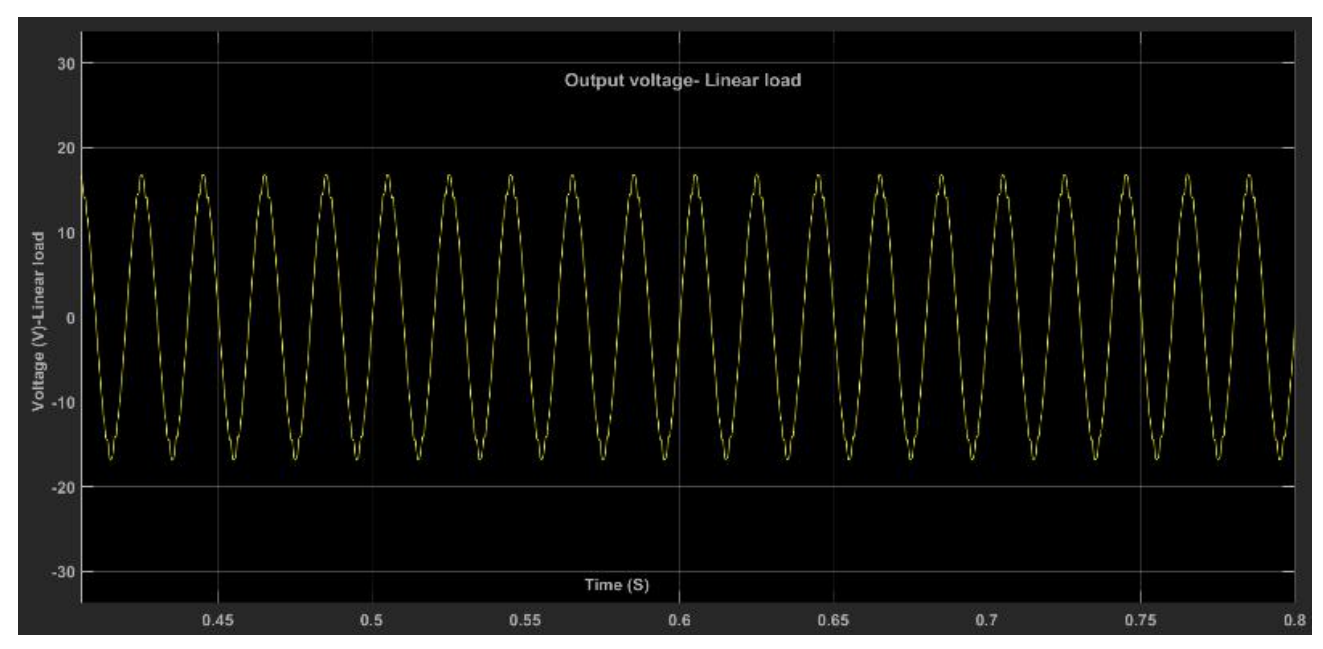

Figure 5a: Output voltage with linear load (1.33A)

Figure 5a shows the output voltage waveform with a resistive load connected across the P-N terminal in the figure5. The RMS voltage measured is $11.47 \mathrm{VAC}$ shown in figure 6 with an output voltage regulation of $+/-2.20 \%$. 


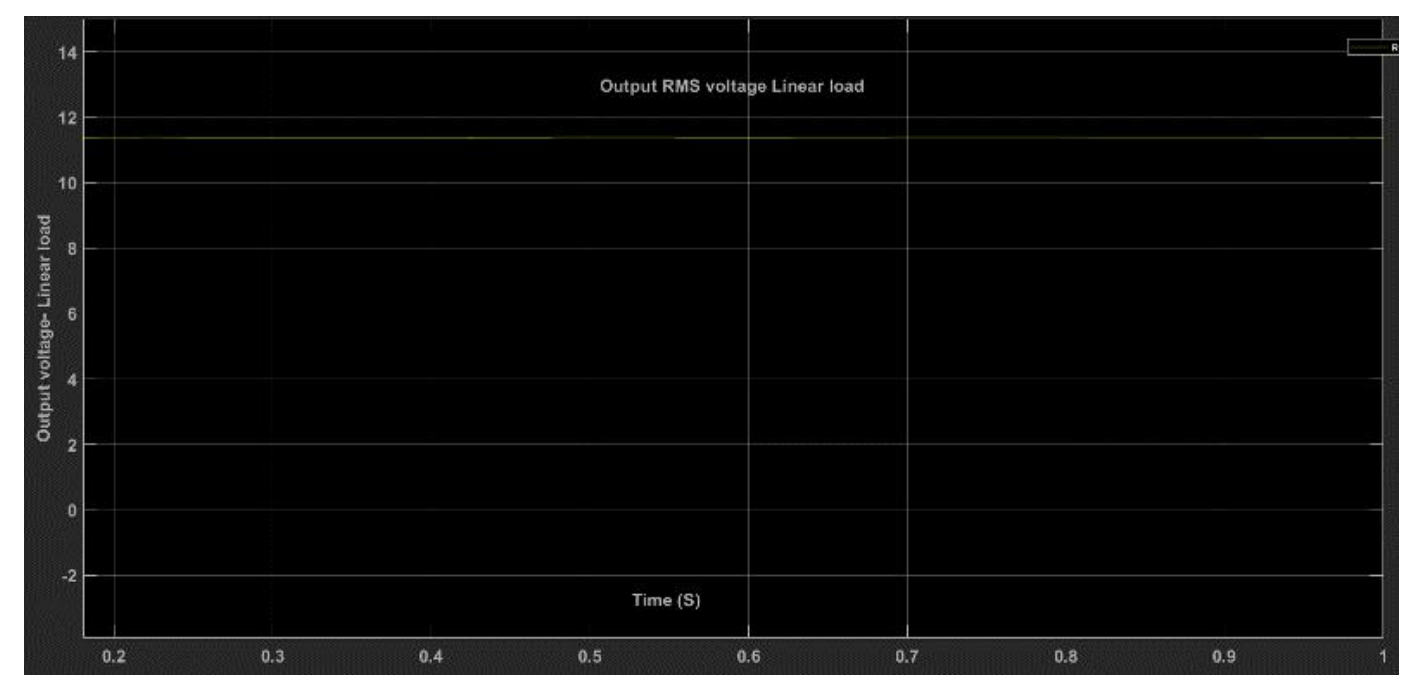

Figure 6: Output voltage RMS (11.47 Volt) linear load

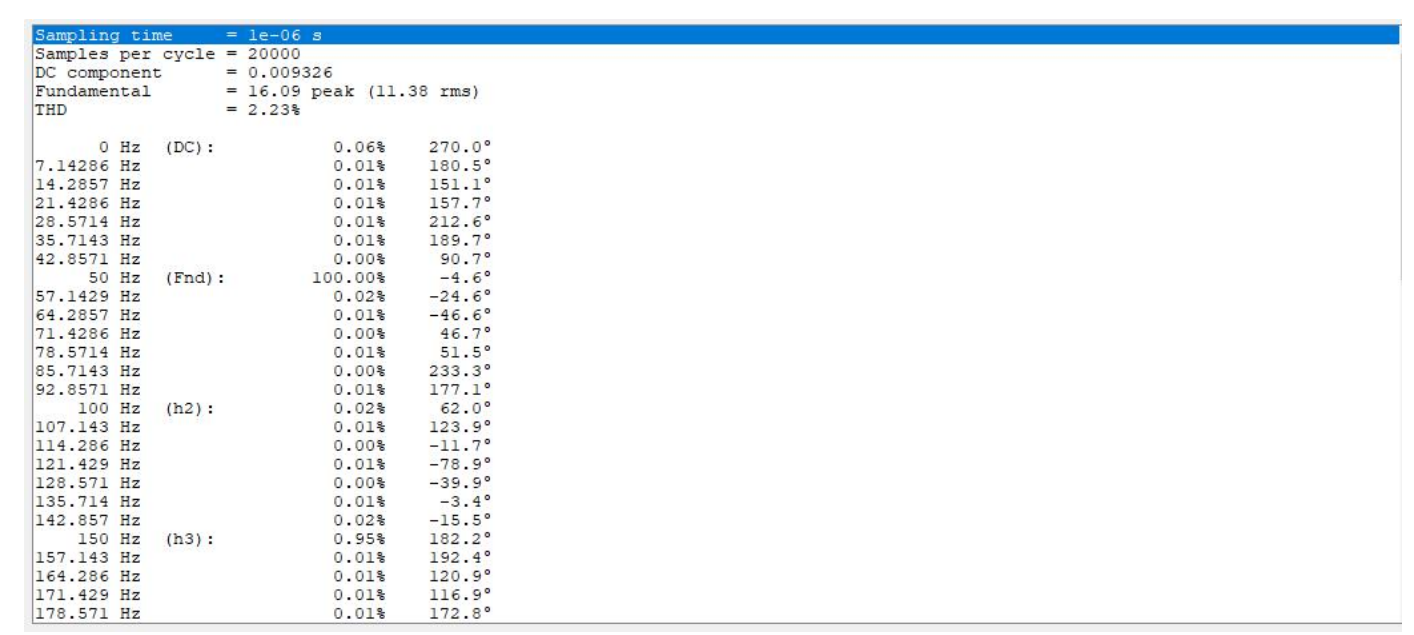

Figure 7: Output voltage THD with linear load (2.23\%)

Figure 7 shows the THD measured till its 10th harmonics of the fundamental frequency and measured at $2.23 \%$. The dominant third harmonics are restrained less than $1 \%$.

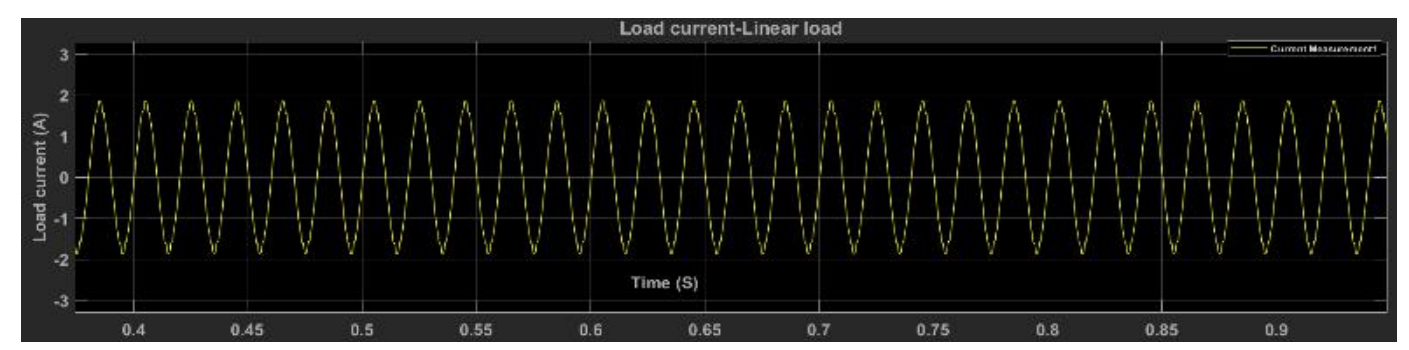

Figure 8: Output current- Linear load (1.33A RMS)

Figure 8 shows the output current shape with a resistive load applied with an amplitude of

\subsection{Ampere.}




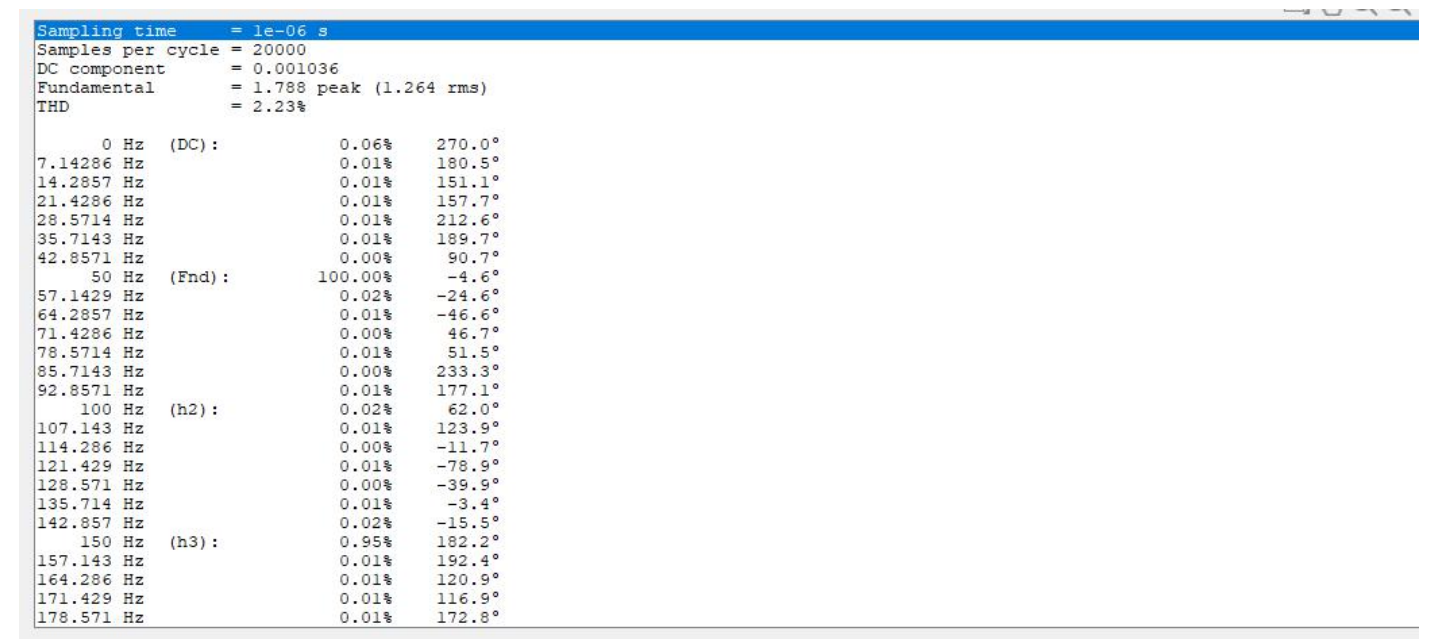

Figure 9: Output current- THD Linear load (2.23\%)

The load current THD is shown in figure 9, the total current harmonic distortion detected is $2.23 \%$.

\section{b) Conventional droop controller- Nonlinear load}

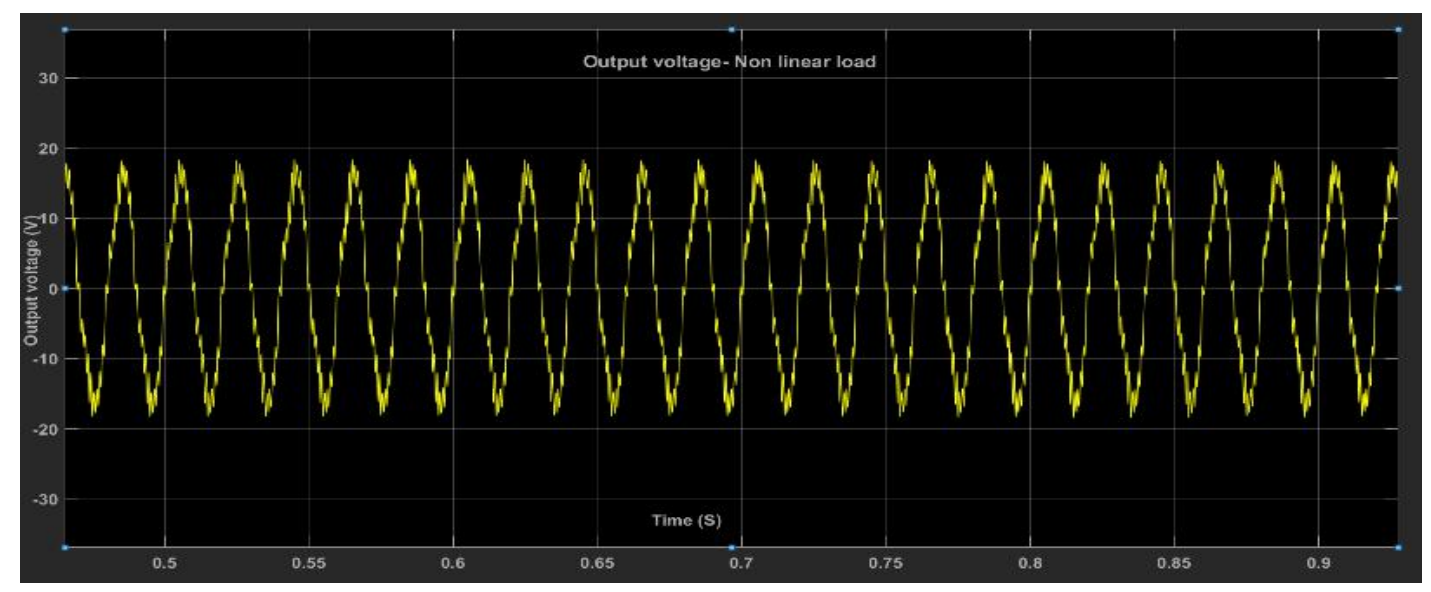

Figure 10: Output voltage nonlinear load

The output voltage of an inverter with nonlinear load with crest factor 3:1 is shown in the figure 10

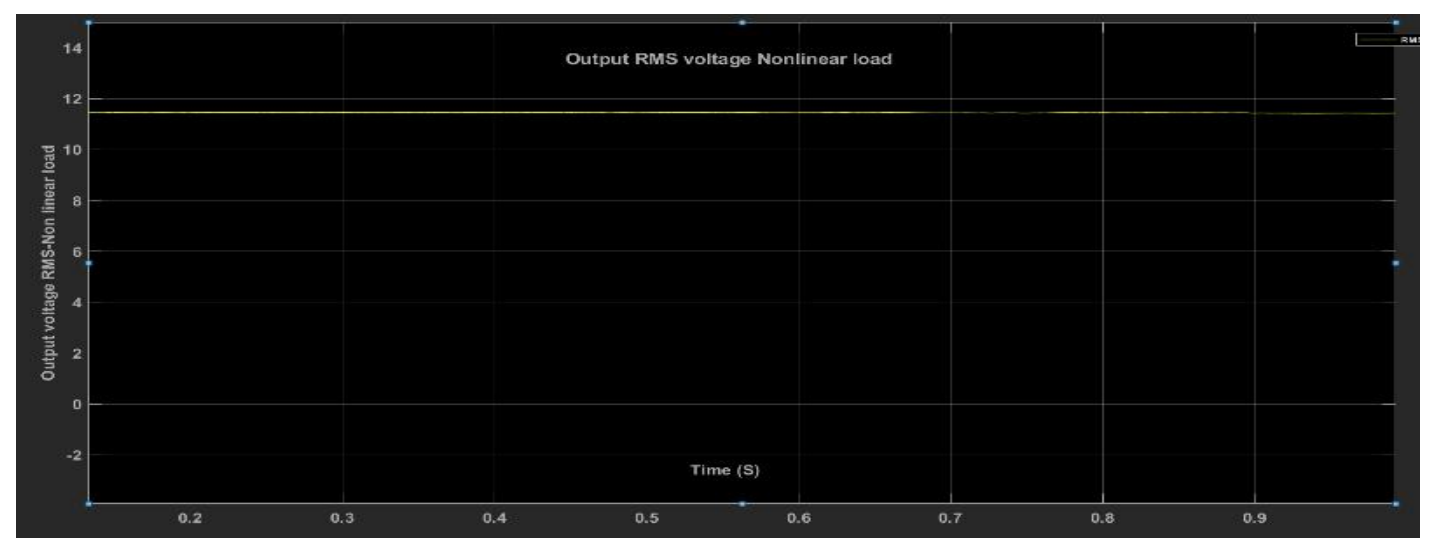

Figure 11: Output voltage RMS (11.41 Volt) Nonlinear load 
The value of output RMS voltage is shown in the figure 11, with an output voltage regulation of $+/-2.46 \%$.

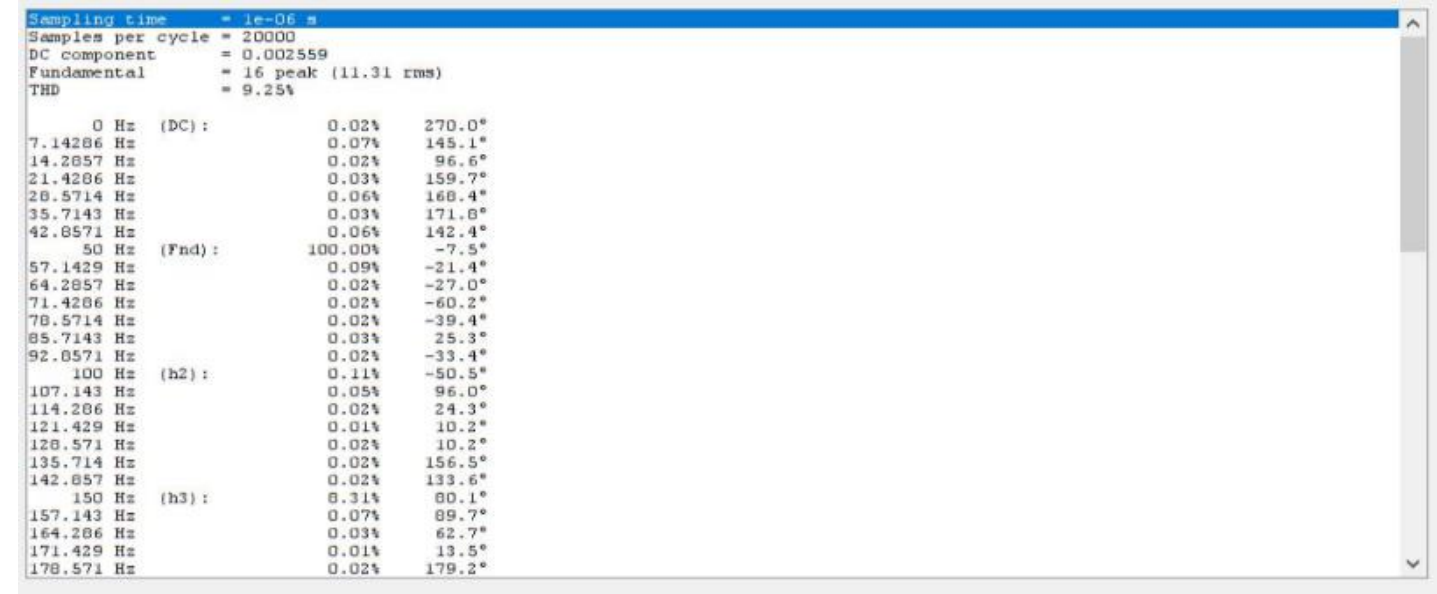

Figure 12: Output voltage THD with nonlinear load $(9.25 \%)$

The voltage harmonic distortion measured with a nonlinear load is $9.25 \%$ shown in figure 12

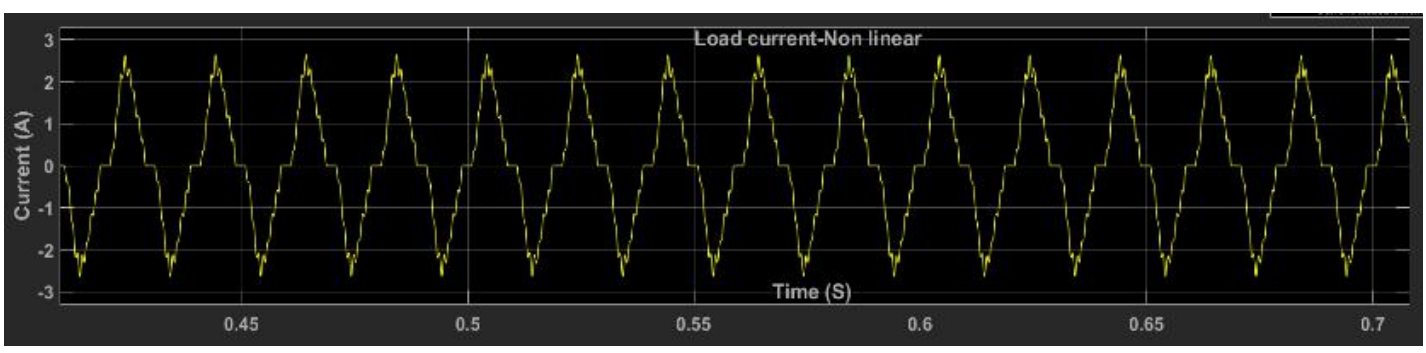

Figure 13: Output Current-Nonlinear load ( 1.33A RMS)

The non-liner load current pattern is shown in the figure 13 with rms value 1.33 Ampere

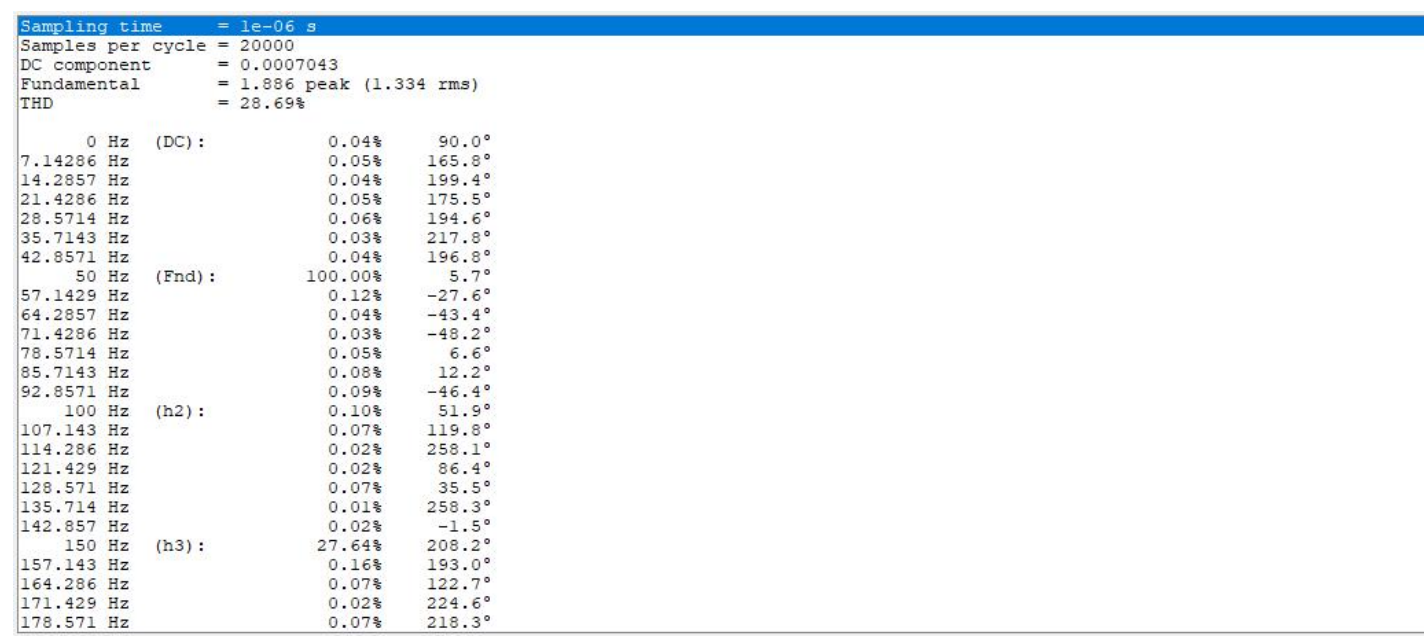

Figure 14: Output current- THD nonlinear load (28.69\%)

The load current THD is measured as $28.69 \%$ at figure 14 with a rms current of $1.33 \mathrm{~A}$, this causes the output voltage THD of $9.25 \%$. 
To improve the output voltage distortion, an enhanced controller method called robust droop control has been implemented, the paper further illustrates about the implementation robust boost controller.

\section{v. Robust droop controller: R Inverter}

Robust droop controller is the advanced version of droop controller where an integral team is added to the voltage loop. An improved droop controller achieves accurate proportional load sharing. The output voltage droop E* -Vo is added to dEi via an amplifier Ke to make sure that the output voltage remains within a certain required range.

In the steady state, the input to the Integrator should be 0 . Hence,

$$
\text { niPi }=\operatorname{Ke}(E *-V o)=\text { constant }
$$

if $\mathrm{Ke}$ is chosen the same. This guarantees accurate real power sharing without having the same $\mathrm{Ei}$. This is more natural than the case with the conventional droop controller. The accuracy of real power sharing no longer depends on the inverter output impedances and is also immune to numerical computational errors and disturbances.

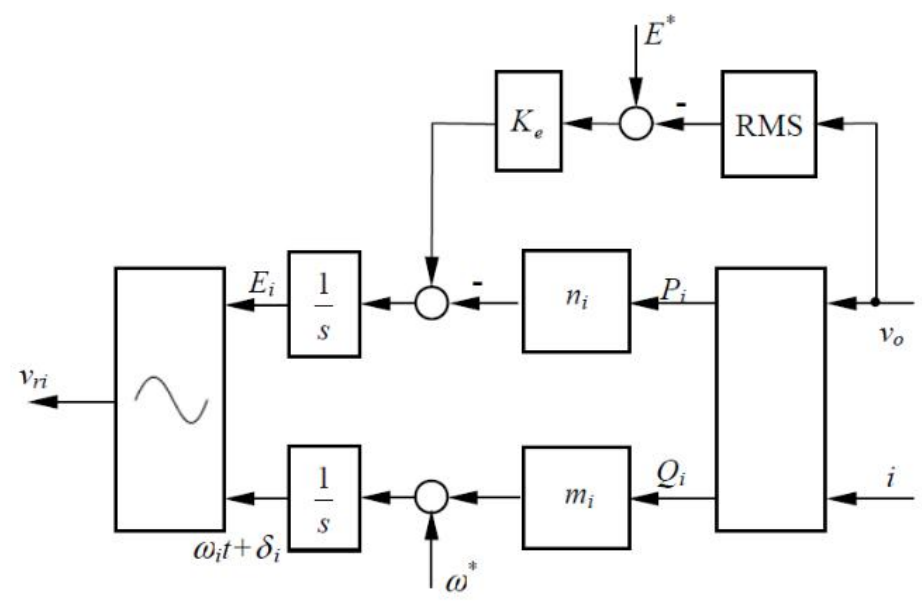

Figure:15 Robust droop control R inverter

The droop coefficients ni and mi are calculated based on the voltage ration defined by $10 \%$ and the frequency boost ratio of $1 \%$.

Therefore, 'ni Pi* $/ \mathrm{KeE} *$ ' $=10 \%$

And the frequency boost ratio ' $\mathrm{mi} \mathrm{Q} i * / \omega *$ ' $=1 \%$, at the rated reactive power $\mathrm{Q} *$ and real power P* 
The Robust droop control algorithm is shown in the figure 15. The output voltage and the voltage THD with resistive load is shown in the figure 16 and figure 17 respectively.

It has been experiential that the voltage THD is $0.91 \%$ up to its $10^{\text {th }}$ harmonics of the fundamental frequency. The RMS output voltage measured in resistive load is 11.87 Volt AC.

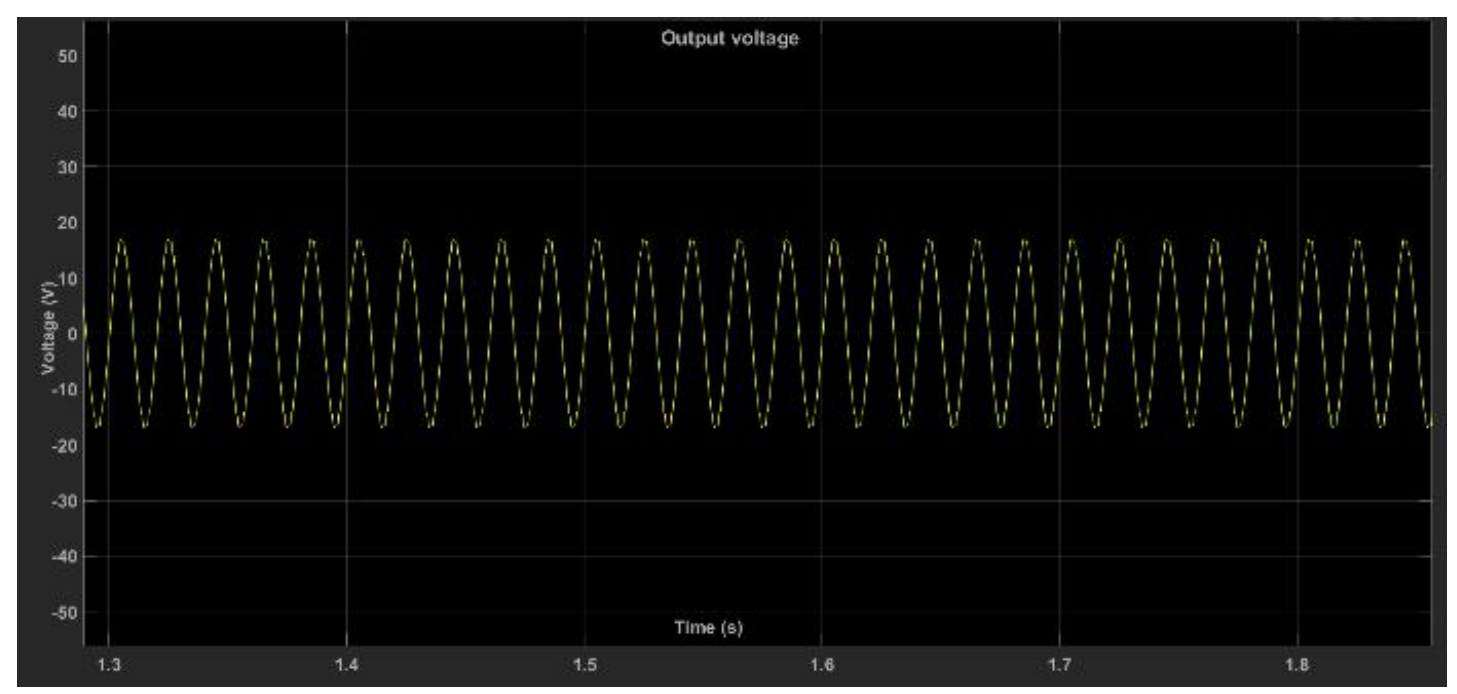

Figure:16 Output voltage

A settling time of $400 \mathrm{~m} \mathrm{sec}$ has been observed for the voltage to stabilize to 12 Volt AC rms as per the set refence.

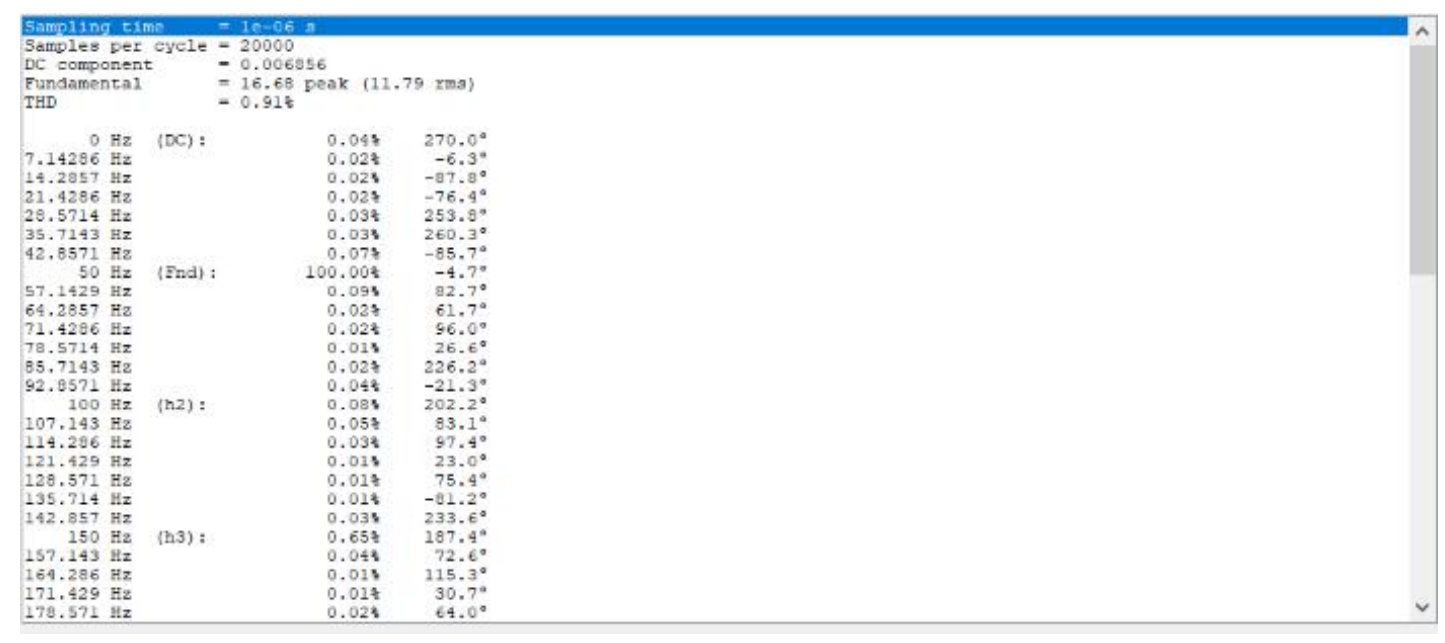

Figure: 17 Output voltage THD

From the figure 17 it has been noticed that the output voltage dominant harmonics are $3 \mathrm{rd}$ and the percentage of distortion is $0.65 \%$. Also, perceived that the output voltage regulation has been improved to $+/-0.54 \%$ for the robust droop controller. The improved voltage measurements are the indirect measurement of its overall harmonic reduction. 


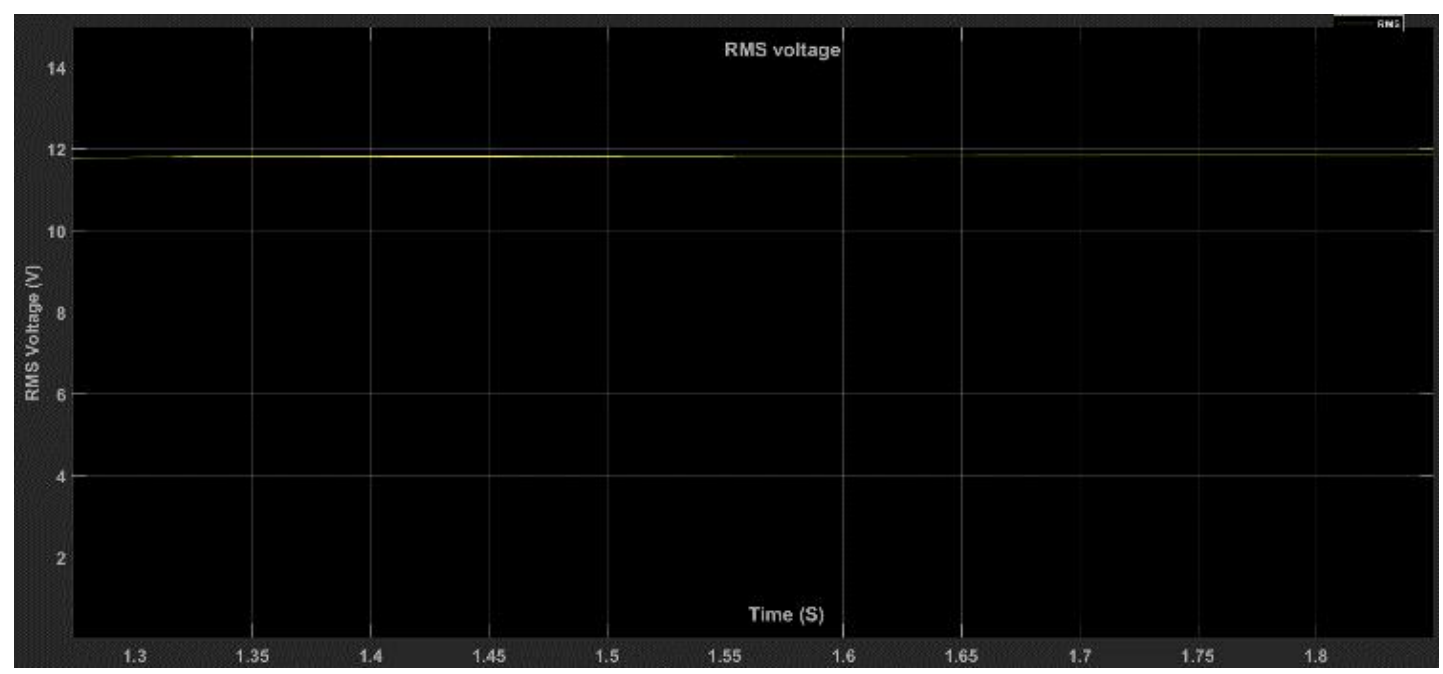

Figure:18 Output voltage (RMS value)

Figure 18 shows the RMS value of the output voltage, the measured value is 11.87 Volt RMS with resistive load.

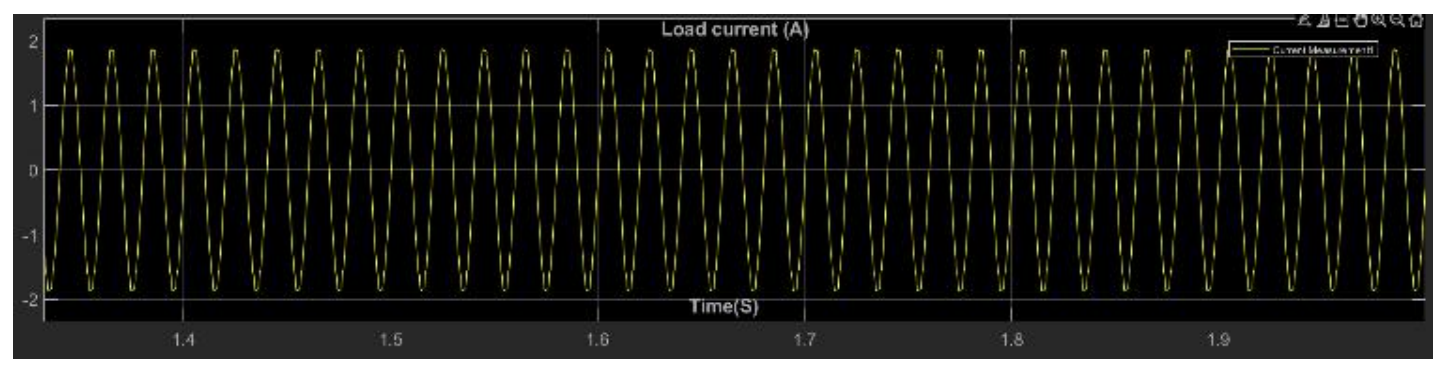

Figure:19 Resistive load current

The load current with RMS value of 1.33 A shown in the figure 19.

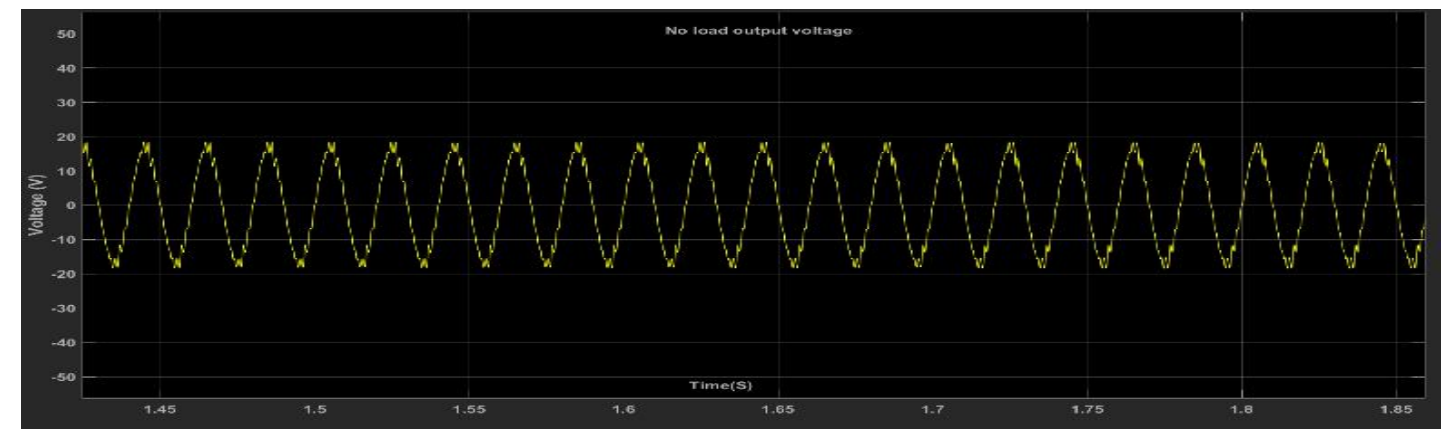

\section{Figure20: No load output voltage}

Figure 20 shows the no load output voltage of the Robust droop controller, RMS voltage measured is 12.02 Volt. The Voltage THD at no load is $1.39 \%$ up to the 10 th harmonics of the fundamental frequency $50 \mathrm{~Hz}$. 


\section{Implementation of a voltage quality controller $K R(s)$ to improve the voltage distortion}

The performance of robust droop controller can be further improved by the implementation of a voltage quality controller KR(s) to deal with the 3rd, 5th, and 7th harmonics and cascade it with the robust droop controller. This can potentially reduce the lower order voltage harmonics, thereby, improve the quality of the power system. Robust droop controller in cascade with an inner loop can improve the sharing, accuracy, voltage regulation and voltage THD, with a compact controller.

The block $K R(s)$ in Figure 21 can be chosen as the resonant harmonic compensators.

The output impedance of the inverter

$$
Z o(s)=s L+K i / 1+K R(s)
$$

so, this can be written for the harmonic's spectrum as

$$
s L+K i / 1+K h
$$

at the frequency $h \omega$. Where ' $h$ ' is the order of the harmonics This helps improve the THD of the output voltage of the inverter, especially the dominant harmonics.

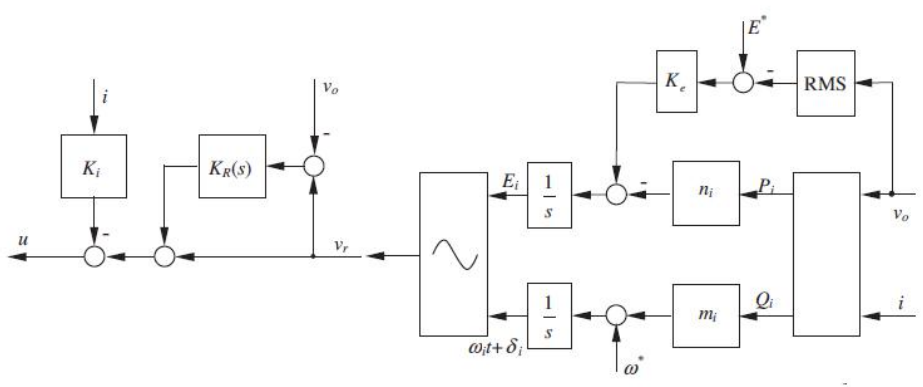

Figure:21 Voltage quality controller implementation

Figure 21 shows the Robust droop control with bypassing harmonic current components algorithm for an R- inverter. Adding an inner loop to improve power quality of the voltage by reducing the dominant lower order harmonics which are the integral multiple of the fundamental $50 \mathrm{~Hz}$ in this case.

$K i$ has the capability of dampening oscillations; it can be chosen to be large so that the impedance at low frequencies is dominantly resistive. In this case it is chosen as 25 . The virtual output impedance is $2 \mathrm{Ohms}$ and based on the equation (8) the $K R(s)$ value for $3^{\text {rd }}, 5^{\text {th }}$ and $7^{\text {th }}$ harmonics are $11.5,13.44$ and 14.082 . To implement $\operatorname{Kr}(\mathrm{s})$ in the inner loop. 
To implement $K R(s)$ A discrete varying notch filter for $3^{\text {rd }} 5^{\text {th }}$ and $7^{\text {th }}$ harmonics are implemented with appropriate gain and damping ratio of 0.7 . These parameters control the notch depth and frequency of the continuous-time notch frequency.

Figure 22 shows the implementation of $K R(s)$ using the notch filter. The outputs of notch filters are added to get the total gain for $3^{\text {rd }}, 5^{\text {th }}$ and $7^{\text {th }}$ harmonics.

The output impedance of the inverter is forced to be principally resistive with a large enough $\mathrm{Ki}$. In addition to the current feedback through the virtual resistor $\mathrm{Ki}$, the voltage error ( $\mathrm{vr}-$ vo) is added to vr through a block $\mathrm{KR}(\mathrm{s})$, which can reduce the output impedance of the inverter at harmonic frequencies. As a result, the high voltage THD caused by a large $\mathrm{Ki}$ when nonlinear loads are present is reduced.

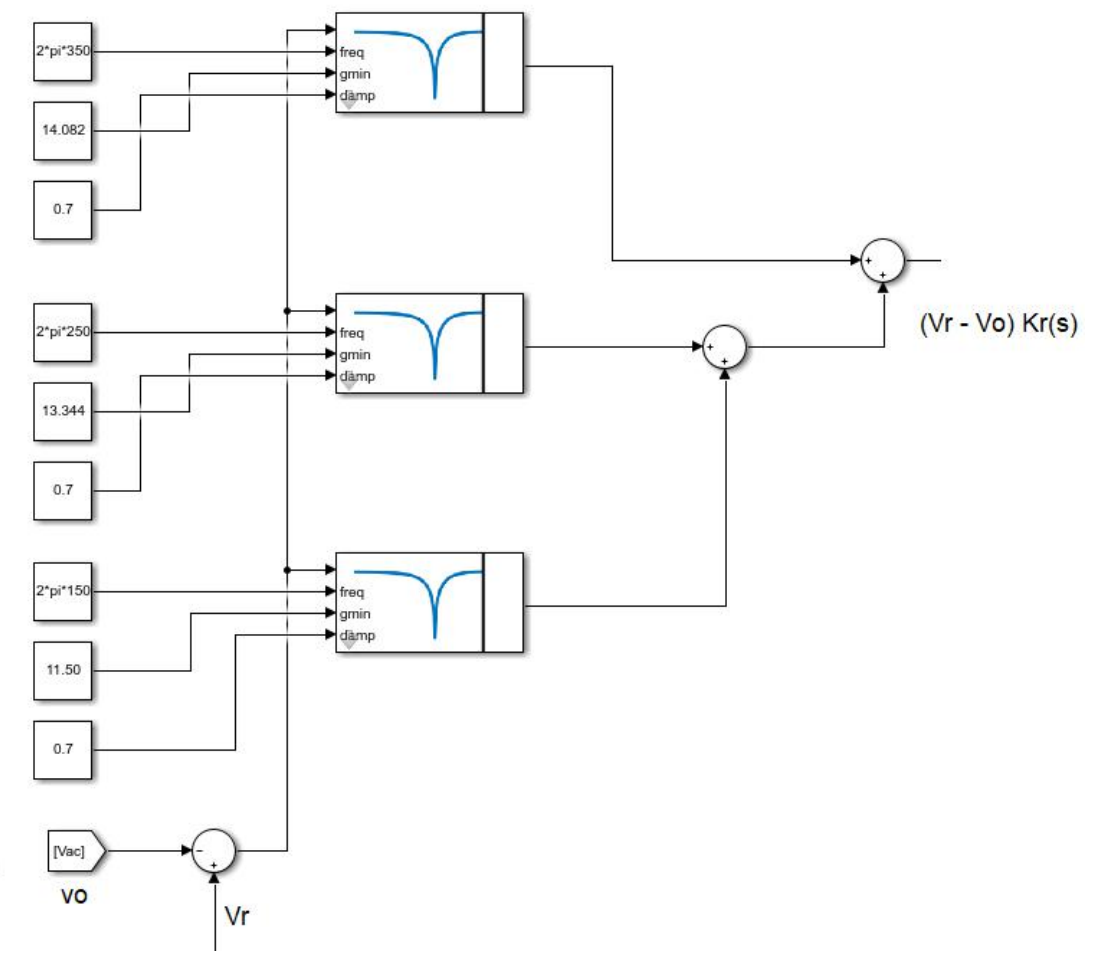

Figure:22 Implementation of $K R(s)$ using a notch filter

The simulation is performed with nonlinear load. Figure 23 shows the output voltage waveform with the nonlinear load is connected to the inverter output. 


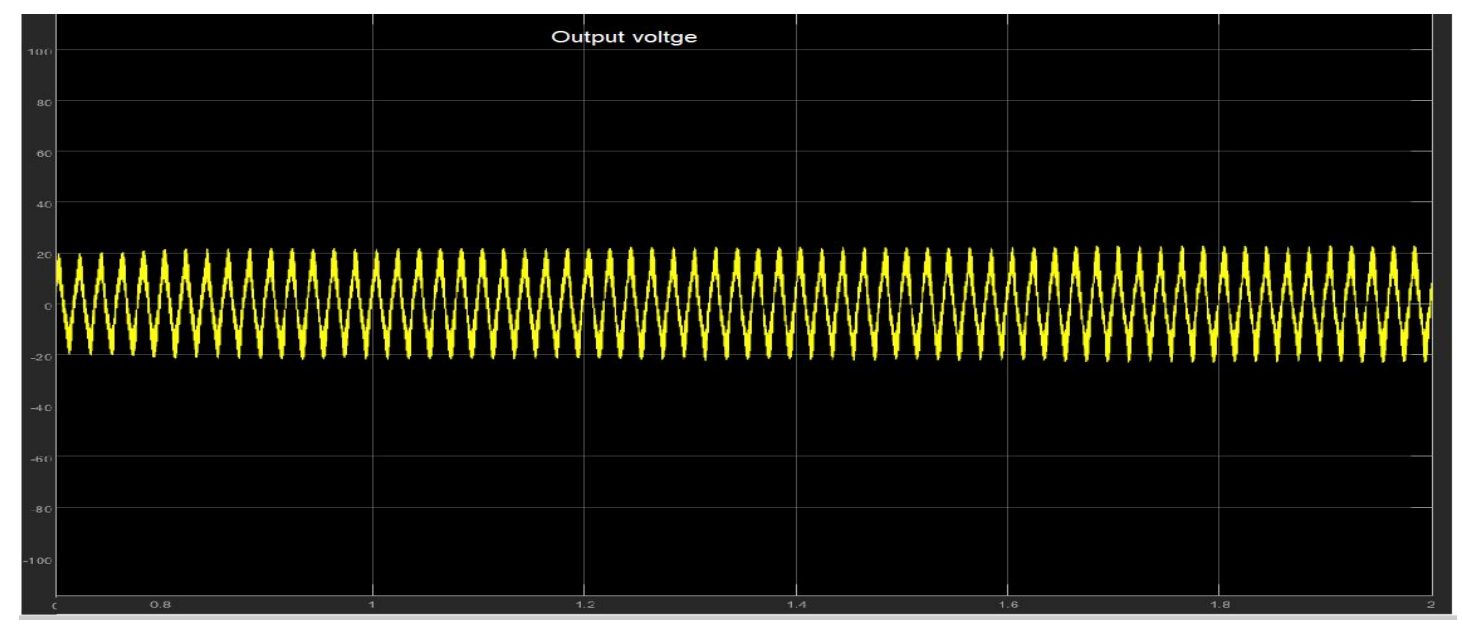

Figure:23 Output voltage

The output voltage is shown in the figure 23 with nonlinear load connected to the inverter output.

The load has got crest factor of 3:1. The output voltage is well regulated to 11.8 volt with a set output voltage of 12 VAC.

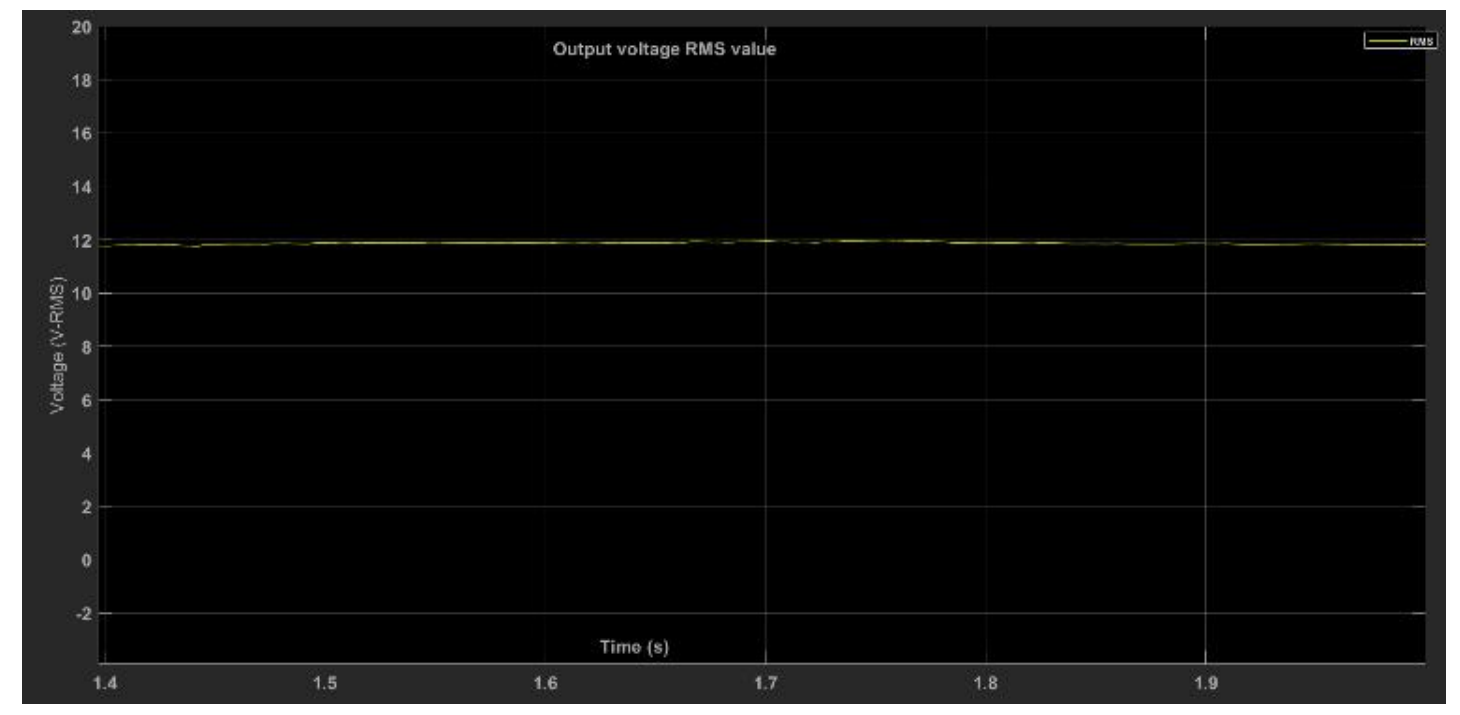

Figure:24 Output voltage RMS value

The RMS value of the output voltage us shown in the figure 24 . The regulation noticed with a crest factor nonlinear load is $+/-0.83 \%$. 


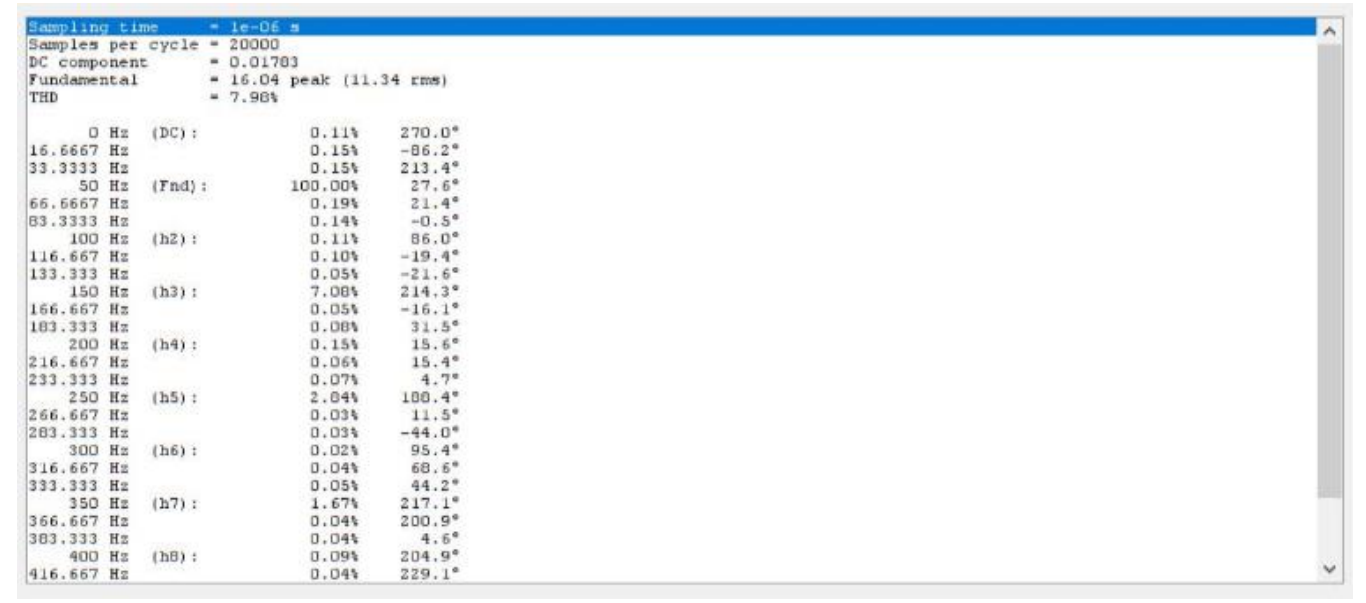

\section{Figure:25 Output voltage FFT}

Figure 25 shows the output voltage THD, the total voltage distortion measured is $7.98 \%$ till its $10^{\text {th }}$ order harmonics, where the $3^{\text {rd }}, 5^{\text {th }}$ and $7^{\text {th }}$ harmonic distortions are $7.08 \%, 2.8 \%$ and $1.67 \%$ respectively.

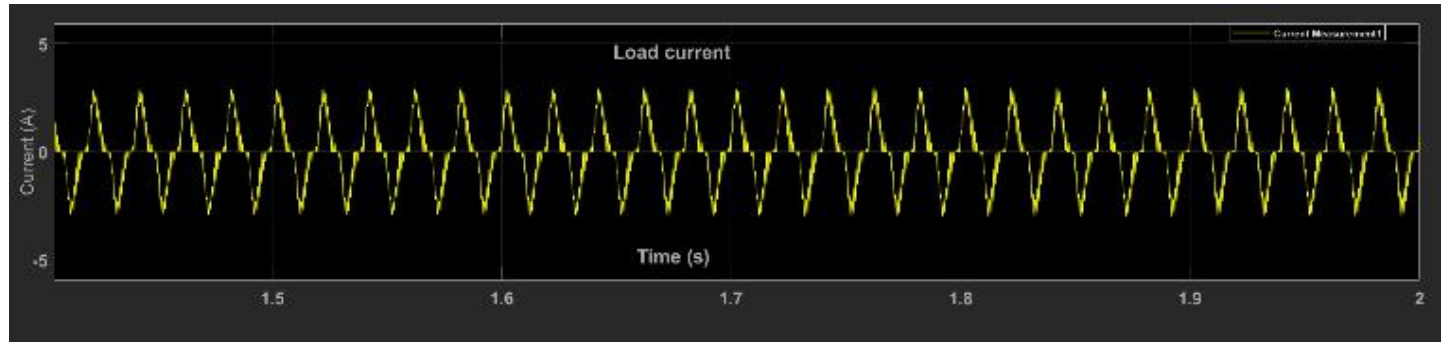

Figure:26 Load current (nonlinear)

Load current waveform is shown at figure 26, the crest factor of the load is 3:1

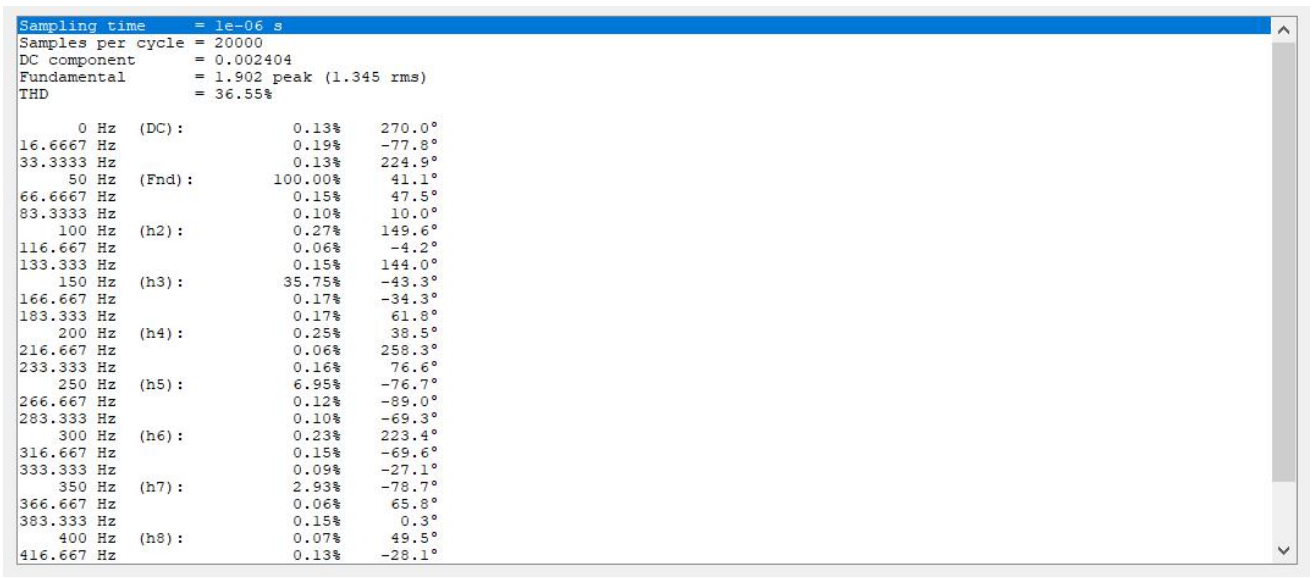

\section{Figure:27 Load current (nonlinear) FFT}

Figure 27 shows the load current FFT. The THD of the load current is measured as $36.55 \%$ up to its $10^{\text {th }}$ harmonics. 


\section{Result consolidation}

For a given nonlinear load, the total voltage harmonic distortion for the conventional droop controller is $9.25 \%$, whereas for the Robust droop controller with harmonics reduction implementation is $7.98 \%$. Even though the load current distortion is $36.55 \%$, which is $\sim 8 \%$ higher than that of the conventional droop controller load set up, the KR(s) implementation still reduces the output voltage distortion closer to $7.98 \%$.

\section{VIII.Conclusion}

The load sharing of inverters when it is connected in parallel is a challenging problem. A droop controller algorithm would be the choice where the inverters can share the load current without having a communication link between the inverters, nevertheless the conventional droop control algorithm has a limitations to control the paraments accurately to have an equal share of load based on the capacity of the inverters. A robust droop controller is offered to achieve precise sharing of both real power and reactive power for different types of inverters while maintaining excellent capability of voltage regulation. The introduction of an additional loop to regulate the output voltage can be bolted onto the conventional droop control to strengthen the strategy and to improve the capability of voltage regulation. Hence, the load voltage can be maintained within the desired range around the rated value.

A nonlinear load can create voltage distortion, high as the load impedance is nonlinear in nature. This can impose voltage harmonics having dominant lower order harmonics basically the integer multiple of its fundamental voltage frequency. These harmonics can generate higher cable losses and interferences that can create the electrical pollutions to the grid. The quality of the inverter output voltage THD can be reduced using an inner current loop cascaded with the Robust droop controller. The inner current loop can reduce the order of dominant harmonic impedances to a lower value, thereby reducing the 3rd, 5th and 7th dominant harmonics appearing in the inverter output voltage.

The inner current loop also can be implemented through a discrete variable notch filter and it has been observed that the damping factor of the notch filter also has an important role in reducing the harmonics, As the damping factor increases the lower order harmonics attainments are on higher side. So, it's appropriate to design the inner loop, notch filter implementing $\operatorname{Kr}(\mathrm{s})$ with a damping factor of $\zeta=0.7071$, A critically damped "response gives the much lower harmonics. 


\section{References}

[1] Universal Droop Control of Inverters With Different Types of Output Impedance QINGCHANG ZHONG1,2, (Senior Member, IEEE), AND YU ZENG2, (Student Member, IEEE)

[2] Q.-C. Zhong, "Robust Droop Controller for Accurate Proportional Load Sharing Among Inverters Operated in Parallel," IEEE Trans. Industr. Electron., vol. 60, no. 4, pp. 1281 1290, April 2013 